\title{
Análise de itens da prova de matemática e suas tecnologias do ENEM que envolvem o conceito de números racionais à luz dos seus significados e representações
}

\author{
Analysis of items of proof of mathematics and technology of ENEM involving the \\ concept of rational numbers in the light of its meaning and representations
}

\author{
Fernanda Andrea Fernandes Silva \\ fernandaandrea@ig.com.br \\ Mônica Lins Santiago \\ monlins@terra.com.br \\ Marcelo Câmara dos Santos \\ marcelocamararecife@gmail.com
}

\begin{abstract}
Resumo
Este artigo se constitui em um recorte da dissertação intitulada "Significados e representações dos números racionais abordados no ENEM. Trata-se da análise de itens da prova de conhecimentos gerais das edições do ENEM de 1998 a 2008 e da prova de matemática e suas tecnologias das edições 2009, 2010 e 2011 que abordam o conceito de números racionais nos seus diferentes significados e representações semióticas. Utilizamos como referencial teórico a teoria das Representações Semióticas de Raymond Duval (2003, 2009, 2011, 2012a e 2012b) e os estudos de Romanatto (1997) e Gomes (2010). Os itens identificados nas provas de matemática e suas tecnologias foram analisados quanto aos registros de representações contidos na estrutura do item e, também, quanto aos registros de representações, os tratamentos e as conversões que poderiam ser mobilizados durante a sua resolução. Concluímos que nem todos os significados dos números racionais foram abordados nessas provas, e o registro numérico percentual foi o mais contemplado nos enunciados dos itens. Encontramos, também, que os itens mobilizam a conversão de registros em apenas um sentido.
\end{abstract}

Palavras-chave: Significados. Representações. Números racionais.

\begin{abstract}
This article constitutes an outline of the dissertation entitled "Meanings and representations of rational numbers addressed in ENEM. It is the analysis of test items of general knowledge of issues ENEM 1998 to 2008 and math test and their technologies editions 2009, 2010 and 2011 that address the concept of rational numbers in their different meanings and semiotic representations. Use as theoretical framework the theory of the Representations Semiotics Raymond Duval (2003, 2009, 2011, 2012a and 2012b) and studies Romanatto (1997) and Gomes (2010). The items identified in math tests and their technologies were analyzed according to records of the representations contained in the structure of the item and also as to the records of the representations, treatments and conversions that could be mobilized during its resolution. We conclude that not all meanings of rational numbers were addressed in these tests, and record numerical percentage was as contemplated in the description of items. We also found that items mobilize the conversion of records in only one direction
\end{abstract}

Keywords: Meanings. Representations. Rational numbers. 


\section{Introdução}

A diversidade de significados e de representações dos números racionais tem sido apontada por pesquisas na área de educação matemática (CATTO, 2000; MERLINI, 2005; TEIXEIRA, 2008) como fatores que dificultam a aprendizagem do conceito dos números racionais na educação básica.

De acordo com Romanatto (1997), o número racional, conforme o contexto em que está inserido, pode significar a parte de um todo (parte-todo), uma divisão em partes iguais (quociente), uma relação de comparação (razão), uma relação entre um número e um ponto na reta numérica (número na reta numérica), uma função que transforma uma quantidade inicial (operador multiplicativo) e a chance de um evento ocorrer (probabilidade). Gomes (2010) aponta também outro contexto como sendo aquele em que o número racional significa uma parte de cem (porcentagem). Esses significados dos números racionais são os adotados nesse estudo.

Por outro lado, como afirma Duval (2003, p.21), “o acesso aos objetos matemáticos passa necessariamente por representações semióticas". Por isso o autor considera importante o sujeito, em uma atividade matemática, ser capaz de mobilizar de forma coordenada os registros semióticos e mudar de registro sempre que se fizer necessário, discriminando, assim, o objeto matemático de sua representação. Tomando como objeto matemático os números racionais, podemos verificar uma diversidade de registros de representações, na forma decimal, fracionária, percentual, figural e na língua natural. Essa diversidade de representações, a coordenação entre esses registros de representação e a diferenciação entre eles e o objeto matemático número racional, são fatores que influenciam na aprendizagem desse campo numérico, de acordo com Maranhão e Igliori (2003).

Como o Exame Nacional do Ensino Médio - ENEM é uma avaliação de larga escala com base nas concepções e habilidades que devem ser desenvolvidas durante a educação básica, esse estudo, com o intuito de suscitar uma reflexão sobre o currículo acerca dos números racionais, teve o objetivo de analisar como são abordados os números racionais no ENEM, quanto aos seus significados e representações. Para isso, utilizamos a Teoria das Representações Semióticas de Raymond Duval e os significados dos números racionais apresentados por Romanatto (1997) e Gomes (2010). 


\section{Sistemas semióticos de representação e suas transformações}

Os registros de representação mudam de acordo com os elementos considerados e o sistema utilizado para produzir uma representação, enquanto que, com o objeto representado, sua maior característica é a invariância (DUVAL 2011). Por exemplo, $0,25, \frac{1}{4}, 25 \%$, são registros de representações do mesmo objeto matemático número racional.

Reconhecer a diferença entre o objeto representado e os seus registros de representação impede que dois registros de representações diferentes de um mesmo objeto sejam considerados como sendo dois objetos diferentes ou, então, que dois registros de representação de dois objetos distintos sejam considerados de um mesmo objeto por apresentarem seus conteúdos parecidos.

A dificuldade cognitiva em reconhecer dois registros de representações de um mesmo objeto reside no fato de esses registros serem parciais, não apresentando ou explicitando o mesmo conteúdo do objeto.

Maranhão e Igliori (2003) citam uma atividade retirada da pesquisa de Catto (2000) para exemplificar a ocorrência do fenômeno da não diferenciação entre representante (registro de representação) e representado (objeto) influenciando na aprendizagem dos números racionais. A tarefa solicitava colocar os sinais de $=$ ou $\neq$, entre os registros numéricos, $(0,5)^{2}$ e $\left(\frac{1}{2}\right)^{2}$. Uma aluna do ensino médio calculou, “ $(0,5)^{2}=0,25 \neq \frac{1}{4}=$ 0,25 " (resposta da aluna). Diante da resposta, as autoras concluíram que a aluna apesar de ter calculado corretamente, considerou 0,25 e $\frac{1}{4}$ como sendo dois números distintos e não registros de representações de um mesmo número racional.

Um registro de representação não será confundido com o objeto representado, lhe dando acesso a esse, quando o sujeito dispor de ao menos dois sistemas semióticos diferentes para produzir esse registro e converter naturalmente de um sistema semiótico a outro, mesmo sem se dar conta dos registros produzidos (DUVAL, 2009).

Associar formas de representação por meio de transformações internas a um sistema de registros semióticos, foi denominada por Duval (2011) como 'tratamentos' e aquelas que necessitam uma mudança do sistema semiótico, 'conversões'. Os tratamentos submetem-se às regras de funcionamento do sistema de registros semióticos em questão. As conversões requerem, sobretudo, uma associação entre as 'variáveis 
cognitivas' referentes a cada sistema. Essa operação não é reversível, sendo, portanto, cognitivamente diferente a operação que converte do sistema de registros semiótico decimal, para o fracionário, por exemplo, daquela que faz a conversão inversa, ou seja do registro fracionário para o decimal.

$\mathrm{O}$ ato de substituir um registro de representação por outro referencialmente equivalente é essencial ao pensamento matemático e exige, geralmente, uma continuidade semântica e uma associação entre os registros que serão substituídos para que faça sentido ao pensamento natural (DUVAL, 2012a). Por exemplo, ao substituir a expressão "Dois mais três igual a cinco" pela expressão matemática $2+3=5$, há uma associação entre o registro na língua natural "dois" e o registro numérico "2", o "mais" e o símbolo "+", o "três" e o "3", o "igual" e o símbolo "=" e o "cinco" e "5", tornando essa substituição mais "natural" ao pensamento humano.

Entretanto, esse autor afirma que

\begin{abstract}
Duas expressões podem ser sinônimas, ou referencialmente equivalentes (elas podem "querer dizer a mesma coisa", elas podem ser verdadeiras ou falsas ao mesmo tempo) e não serem semanticamente congruentes: neste caso, há um custo cognitivo importante para a compreensão. (Duval, 2012a, p. 100).
\end{abstract}

Segundo o mesmo autor, transformar uma expressão ou informação contida num sistema semiótico em outra, em outro sistema, pode se tornar um obstáculo na aprendizagem de matemática de vários alunos, devido ao fato de a equivalência referencial distinguir-se da congruência semântica, mas o pensamento espontâneo priorizá-la.

A expressão no registro da língua natural, "um quarto mais um meio" é semanticamente congruente e referencialmente equivalente à expressão no registro numérico fracionário, $\frac{1}{4}+\frac{1}{2}$, entretanto, a substituição do número no registro numérico decimal, 0,5 , para o registro numérico fracionário, $\frac{1}{2}$, possui a característica de ser referencialmente equivalente, mas não é semanticamente congruente. 


\section{A apreensão de figuras geométricas}

Alguns itens dos ENEM que iremos analisar apresentam desenhos nos quais iremos identificar o tipo de apreensão(ões) que são necessárias para a devida compreensão e resolução do item.

As figuras geométricas contidas no contexto das atividades matemáticas são percebidas de duas maneiras diferentes e, na maioria das vezes, contraditórias, de acordo com Duval (2012b). A primeira maneira seria instantânea, relacionada à apreensão perceptiva das figuras geométricas, e a segunda maneira seria discursiva em relação aos elementos figurais. Essas maneiras de apreensão são contraditórias porque o desenho relativo à figura geométrica pode evidenciar elementos que não estão contidos no enunciado, enquanto que esse pode trazer dados sobre o desenho que podem não serem vistos, de modo espontâneo.

Assim, o autor acima citado afirma que o registro figural ${ }^{1}$ que se constitui no desenho da figura geométrica faz originar interpretações próprias para a situação, identificadas como sendo apreensões: sequencial das figuras, perceptiva, discursiva e operatória.

A apreensão sequencial é necessária nas atividades que requerem a construção ou reprodução de uma figura geométrica. A apreensão perceptiva seria aquela que ocorre de forma espontânea na visualização do desenho relativo à figura geométrica, e visa à percepção das suas formas. A apreensão discursiva é necessária na articulação entre os elementos (propriedades e hipóteses) das figuras geométricas contidos no enunciado do problema, no registro da língua natural, e o desenho, no registro figural.

A apreensão operatória é centrada nas modificações possíveis de ocorrer no desenho da figura geométrica de origem e na forma de rever perceptivamente essa figura a partir dessas modificações. Essas modificações podem ocorrer por meio da subdivisão do desenho, denominada modificação mereológica; como também aumentando-o, diminuindo-o ou deformando-o, chamada modificação ótica; ou ainda, deslocando-o ou rotacionando-o em relação ao campo ao qual se encontra, sendo denominada modificação posicional.

\footnotetext{
${ }^{1}$ Duval (2012b) denomina registro de representações espaciais.
} 


\section{Percurso metodológico}

Para investigar como são abordados os números racionais no Exame Nacional do Ensino Médio - ENEM, à luz de seus significados e das suas representações a análise foi dividida em duas etapas.

$\mathrm{Na}$ primeira etapa buscamos analisar as provas de conhecimentos gerais das edições de 1998 a 2008 e das provas de matemática e suas tecnologias das edições de 2009 a 2011 (Novo ENEM), para identificar os itens que contemplavam o conceito de números racionais nos seus diferentes significados.

Na segunda etapa visamos analisar os itens identificados na primeira etapa, referente às provas de matemática e suas tecnologias das edições de 2009 a 2011, no sentido de identificar os registros de representações contidos na estrutura do item, os tratamentos e as conversões que podem ser mobilizados durante a resolução do item.

\subsection{Categorias de análise}

Para identificar os itens das provas de conhecimentos gerais dos ENEM de 1998 a 2008 e das provas de matemática e suas tecnologias dos ENEM de 2009 a 2011, que mobilizavam o conceito de números racionais nos seus diferentes significados, adotamos como categoria preliminar de análise a classificação dos significados de números racionais proposta por Romanatto (1997):

Medida (parte-todo )- expressa uma relação entre partes iguais que são tomadas de uma unidade considerada e o seu total, estando presente a ideia de quantidade e medida. É um dos primeiros contextos que são estudados pelo aluno iniciante no campo dos racionais.

Quociente - expressa uma divisão no contexto de partição ou cota. Por exemplo, dividir 3 chocolates para 4 pessoas (partição).

Razão - expressa uma relação comparativa multiplicativa entre duas quantidades de mesma grandeza ou de grandezas diferentes. Se as grandezas forem diferentes, mas uma depender da outra, então a razão é denominada taxa. Um exemplo de razão com quantidades de mesma grandeza seria: existem três mulheres para cada dois homens; ou como taxa: a velocidade, como uma relação entre distância e tempo. 
Operador multiplicativo - expressa uma relação de transformação de uma quantidade ou medida inicial, ou ainda uma proporcionalidade. Por exemplo, o número que multiplicado por 2 e tem como resultado 3 é o operador $3 / 2$.

Número na reta numérica - expressa a correspondência entre um número racional a um ponto da reta numérica. De acordo com algumas pesquisas como, Nunes e Silva (2009), este é um significado em que os alunos mais apresentam dificuldades de compreensão.

Probabilidade - expressa a ideia de chance em um contexto de relação parte-todo. De acordo com Romanatto (1997), nesse significado, o número racional pode ser visto como uma comparação entre chances favoráveis e possíveis de um evento ocorrer. Por exemplo, calcular a chance de se retirar uma bola azul de uma caixa com 05 bolas azuis, 03 bolas verdes e 02 bolas amarelas.

Porcentagem - nesse contexto o símbolo \% representa por cento ou sobre 100, e são utilizadas frações centesimais que representam a taxa percentual. Gomes (2010), afirma que "é muito comum os alunos enxergarem as porcentagens como um conceito matemático com vida própria" (idem, p. 68), por esse motivo consideramos como mais um significado dos números racionais.

A análise dos registros de representações semióticas dos números racionais foi realizada, a priori, com base na classificação proposta por Duval (2003) dos registros de representações semióticas dos números racionais. A partir dessa análise, categorizamos os registros dos números racionais, identificados na etapa II, de acordo com a classificação abaixo:

Registro numérico fracionário $(R N F)$ : quando o número racional, ou expressão numérica de números racionais, envolve números na forma $\frac{\mathrm{a}}{\mathrm{b}}, \operatorname{com} \mathrm{b} \neq 0$. Ex: $\frac{3}{4}$.

Registro numérico decimal (RND): quando o número racional, ou a expressão numérica de números racionais, envolve números na forma de números acompanhados com vírgula, e que podem ser transformados na forma $\frac{\mathrm{a}}{\mathrm{b}}$, com $\mathrm{b} \neq 0$. Ex: 3,$4 ; 0,999 \ldots ; 2,12+$ 35.

Registro numérico percentual (RNP): quando o número racional, ou a expressão numérica de números racionais, tem números na forma de número acompanhado com o símbolo \%. Ex: a expressão 9,8\% . 250000. 
Registro numérico potência de dez (RNPD): quando o número racional está na forma de notação científica ou produto de potência de dez. Ex: 1,5 x 10².

Registro algébrico (RA): quando o numerador ou denominador de uma fração, ou ambos, são incógnitas ou variáveis, podendo a fração fazer parte de uma expressão ou equação, o número racional na forma decimal vir acompanhado de uma incógnita, ou ainda o quando o número racional na forma percentual é a incógnita ou faz parte de uma expressão ou equação que contém uma incógnita. Ex: a expressão, $\frac{\mathrm{BC}}{2} \times \mathrm{BC}$; ; equação $0,30 x+0,20 x \cdot 0,30 x=3800$, equação $x \% .132000=13000$.

Registro figural $(R F) l$ : quando o número racional está representado por meio de uma quantidade contínua ou discreta, ou, ainda, na reta numérica.

A análise dos outros registros de representações semióticas contidos no item, ou que poderiam ser mobilizados durante a resolução do mesmo, teve como base a classificação proposta por Duval (2003), dos registros de representações semióticas. Partindo dessa análise, categorizamos os outros registros de representações presentes ou mobilizados nos itens, conforme a seguinte classificação:

Registro na língua materna - são os textos, que comportam os enunciados e comandos dos itens.

Registro numérico inteiro - são as representações numéricas dos números naturais, inteiros relativos que fazem parte do conjunto dos números racionais. Ex: 28, -4.

Registro em diagrama - é aquele que relaciona quatro valores numéricos ou algébricos (sendo dois valores relativos e dois absolutos, na maioria das vezes), sendo um desses a incógnita, dispostos em forma de colunas, em que cada coluna corresponde ao valor relativo e ao respectivo universo. Esse registro é utilizado para estabelecer a regra de três, em uma conversão em que o registro de partida é o da língua materna. Ex: a regra de três, $100 \% 56 \%$

Registro de tabela - é aquele que dispõe os dados em linhas e colunas.

Registro Gráfico - correspondem a todos os tipos de gráficos de, linhas, barras e colunas.

Registro figural - é aquele que representa figuras geométricas em até três dimensões. 
Registro de quadro - é aquele que apresenta um quadro, trazendo dados necessários à resolução do item.

O registro em diagrama foi assim tipificado por sentirmos a necessidade de nomear o registro que é intermediário entre o registro da língua materna e o registro algébrico proporcional, e tem o objetivo de organizar os dados necessários a esse último registro.

A análise dos tratamentos realizados nos registros de representações semióticas ocorreu de acordo com a estratégia de resolução (canônica) que poderia ser mobilizada no item, e foram categorizados de acordo com os registros em que ocorriam.

A análise das conversões entre os registros de representações semióticas também dependeu da estratégia de resolução (canônica) que poderia ser mobilizada na resolução do item e foi categorizada de acordo com o sistema semiótico que o registro se encontrava inicialmente (registro de partida), e para o qual ele foi transformado (registro de chegada).

Os tipos de apreensões geométricas foram classificadas de acordo com Duval (2012b) em:

Sequencial das figuras - é aquela utilizada em construções ou reproduções de figuras geométricas.

Perceptiva - é aquela utilizada para visualizar o desenho da figura geométrica.

Discursiva - é aquela utilizada para relacionar as propriedades da figura geométrica com o seu respectivo desenho.

Operatória - é aquela utilizada para modificar o desenho da figura geométrica.

\section{Itens dos ENEM de 1998 a 2011 que contemplam o conceito de números racionais}

Da análise das provas de conhecimentos gerais dos ENEM de 1998 a 2008 foram identificados 41 itens e das provas de matemática e suas tecnologias dos ENEM de 2009 a 2011, 29 itens, totalizando 70 itens que contemplam o conceito de números racionais, nos seus diferentes significados. 
Nas provas de conhecimentos gerais dos ENEM de 1998 à 2008 identificamos uma média de 3,5 itens, por prova, que contemplam algum tipo de significado e representação dos números racionais, o que corresponde a aproximadamente 5,6\% do total de 63 itens que continha cada prova.

Já nas provas de matemática e suas tecnologias do novo ENEM, que corresponde ao período de 2009 à 2011, foram encontrados, em média, 9,6 itens por prova que abordam algum tipo de significado e representação dos números racionais, correspondendo a aproximadamente $21 \%$ do total de 45 itens da prova. Esse resultado pode estar indicando a necessidade e a importância do aluno saber mobilizar o conceito dos números racionais na resolução dos itens do ENEM.

$\mathrm{O}$ crescimento no número de itens por prova que abordam o conceito dos números racionais, no novo ENEM se comparado com os ENEM de 1998 a 2008, pode ter se dado pelo fato de a nova versão desse exame constar de uma prova de matemática e suas tecnologias com 45 itens, enquanto que a versão antiga constava de 63 itens envolvendo não só matemática e suas tecnologias, como também, as áreas de cências da natureza e ciências humanas. Além disso, o novo ENEM assume um outro caráter que é o de servir como processo seletivo para o ensino superior, o que pode estar indicando que o crescimento no número de itens que envolve o conceito de números racionais, se deve à importância desse conhecimento não só no cotidiano das pessoas, quanto na vida acadêmica; e a consequente necessidade de ser avaliado entre os concluintes e egressos do ensino médio.

\section{Significados dos números racionais nas provas de conhecimentos gerais dos ENEM de 1998 à 2008 e de 2009 à 2011 (novo ENEM)}

Nas provas de conhecimentos gerais dos ENEM de 1998 a 2008 foram identificados 41 itens que mobilizam o conceito de números racionais nos significados operador multiplicativo, parte-todo, razão, porcentagem e probabilidade. Alguns desses itens envolvem mais de um significado do número racional

Desses itens identificados como mobilizadores de algum tipo de significado do número racional, $61 \%$ abordam o significado porcentagem, 34,1\% razão, 14,6\% probabilidade, 9,7\% parte-todo e não conseguimos identificar nenhum item que envolvesse os significados quociente e número na reta numérica. Esses resultados podem ser 
justificados devido ao fato de o ENEM priorizar situações que envolvam contextos econômicos e sociais, ou seja, relacionados à cidadania, nos quais os significados porcentagem, razão e probabilidade podem se fazer mais frequentes.

Nas provas de matemática e suas tecnologias dos ENEM 2009, 2010 e 2011 (novo ENEM) foram identificados 29 itens que envolvem os números racionais nos seus diferentes significados e representações, sendo que aproximadamente $55 \%$ desses abordam o significado porcentagem, 24\% o significado razão, 17\% o significado probabilidade, $10 \%$ o significado parte-todo e $6 \%$ abordam mais de um significado.

Se compararmos os dados referente aos itens das duas versões do ENEM, verificamos que há uma tendência desse exame em priorizar o significado porcentagem, seguido pelo significado razão, probabilidade e parte-todo.

\section{Análise dos itens selecionados da prova de matemática e suas tecnologias dos ENEM 2009, 2010 e 2011}

Das provas de matemática e suas tecnologias do ENEM 2009, 2010 e 2011 foram selecionados 29 itens que contemplam o conceito de números racionais nos seus diferentes significados e representações. Para analisá-los quanto aos registros de representações (dos números racionais ou não) existentes no item e aqueles que podem ser mobilizados na resolução do mesmo, os tratamentos e as conversões contempladas durante essa resolução, traçamos um roteiro que é seguido para todos os itens, conforme abaixo:

1) estratégia esperada de resolução, incluindo tratamentos e conversões (quando houver);

2) outra(s) estratégia(s) de resolução (quando for pertinente);

3) análise do suporte (quando houver);

4) estrutura do item, quanto aos registros de representações envolvidos;

5) alguns comentários referentes às habilidades necessárias à resolução do item e outros conceitos exigidos (quando for pertinente);

Como exemplo da análise realizada nesses itens, temos abaixo dois itens retirados, respectivamente, do ENEM 2009 e da edição 2011. 


\section{Item 01/2009}

Figura 2 - Questão 137 da prova de matemática e suas tecnologias do ENEM 2009

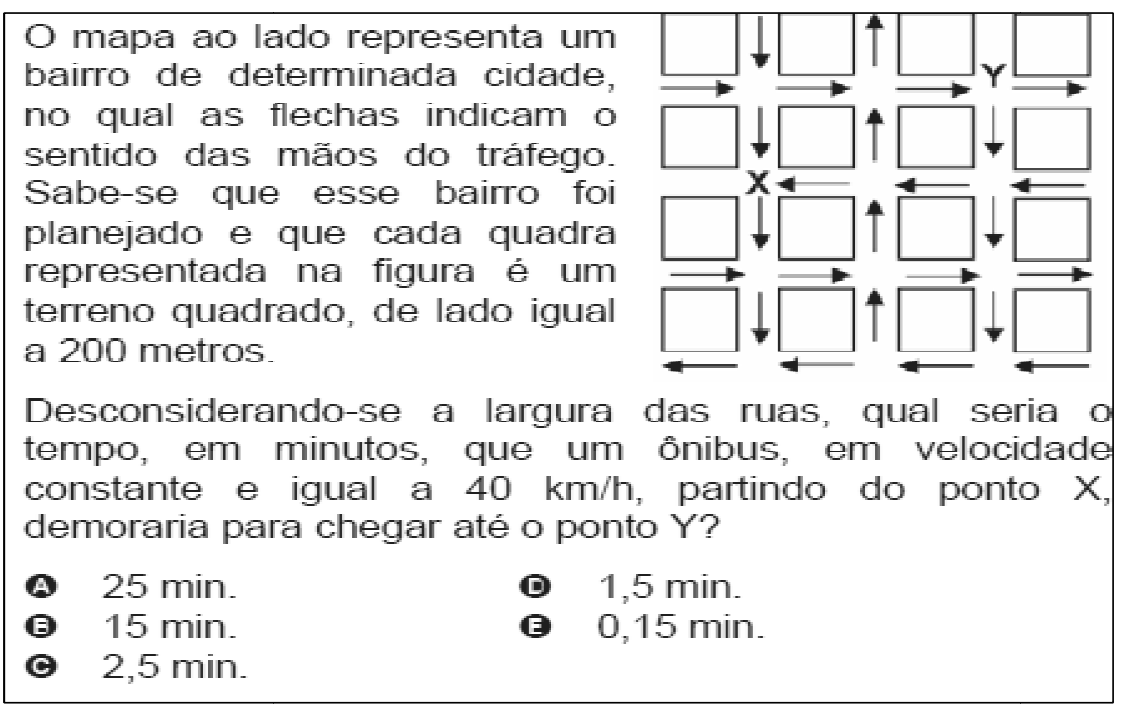

Fonte: BRASIL (2009d), p. 19.

1) Estratégia esperada de resolução:

\begin{tabular}{|c|c|c|}
\hline & Ação & Transformação \\
\hline $\mathbf{1}$ & $\begin{array}{l}\text { Descrever o percurso de } \mathrm{x} \text { a y e estabelecer que o } \\
\text { tempo gasto é a razão entre o espaço percorrido pelo } \\
\text { ônibus e a velocidade }\left(\frac{\mathrm{s}}{40 \mathrm{~km} / \mathrm{h}}\right) .\end{array}$ & $\begin{array}{l}\text { Conversão da língua materna para o registro } \\
\text { algébrico. }\end{array}$ \\
\hline 2 & Calcular o espaço percorrido pelo ônibus $\left(5_{x} 200 \mathrm{~m}\right)$ & $\begin{array}{l}\text { Conversão do registro figural para o numérico } \\
\text { inteiro. }\end{array}$ \\
\hline 3 & $1000 \mathrm{~m} \mathrm{em} 1 \mathrm{~km}$ & nento no registro numérico inteiro \\
\hline 4 & $\begin{array}{l}\text { Substituir o valor encontrado na ação } 3 \text {, na razão, da } \\
\text { ação } 1 \text { para encontrar o tempo gasto pelo ônibus } \\
\text { para o percurso de } \mathrm{X} \text { a Y. }\left(\frac{1}{40} \mathrm{~h}\right)\end{array}$ & Tratamento no registro numérico fracionário \\
\hline 5 & Transformar para minutos $\left(\frac{60}{40} \mathrm{~min}\right)$ & Conversão de horas para minutos. \\
\hline 6 & $\begin{array}{l}\text { Simplificar a fração }\left(\frac{3}{2} \min \right) \text { e transformá-la em } \\
\text { decimal; ou apenas transformar a fração }\left(\frac{60}{40} \min \right) \\
\text { em decimal }(1,5 \mathrm{~min})\end{array}$ & $\begin{array}{l}\text { Tratamento no registro numérico decimal e } \\
\text { conversão do registro numérico fracionário para o } \\
\text { decimal; ou apenas a referida conversão. }\end{array}$ \\
\hline
\end{tabular}

2) Análise do suporte:

O suporte requer uma apreensão discursiva, pois o registro figural será analisado de acordo com o registro discursivo, no enunciado do item, no sentido de encontrar o espaço percorrido pelo ônibus; 
3) Estrutura do item:

\begin{tabular}{|l|l|}
\hline Ideia envolvida & Razão (taxa) \\
\hline Registro do enunciado & Língua materna e numérico inteiro \\
\hline Registro do suporte & Geométrico \\
\hline Registro do comando & Língua materna e numérico inteiro \\
\hline Registro das alternativas de resposta & Numérico decimal e inteiro \\
\hline
\end{tabular}

4) Alguns comentários

O item requer que o sujeito compreenda o conceito de velocidade constante como uma relação entre distância e tempo, e saiba realizar transformações nas unidades de medida de comprimento e de tempo.

\section{Item 1/2011}

Figura 2 - Questão 145 da prova de matemática e suas tecnologias do ENEM 2011

Café no Brasil
O consumo atingiu o maior nivel da história no ano
passado: os brasileiros beberam o equivalente a 331
bilhões de xícaras.
Veja. Ed. 2158, 31 mar. 2010.
Considere que a xícara citada na notícia seja equivalente
a, aproximadamente, 120 mL de café. Suponha que em
2010 os brasileiros bebam ainda mais café, aumentando
o consumo em $\frac{1}{5}$ do que foi consumido no ano anterior.
De acordo com essas informações, qual a previsão mais
aproximada para o consumo de café em 2010?
A 8 bilhões de litros.
B 16 bilhões de litros.
C 32 bilhões de litros.
() 40 bilhões de litros.
E) 48 bilhões de litros.

Fonte: BRASIL (2011), p. 25. 
1) A estratégia esperada de resolução envolve os dados na medida em que estão dispostos no problema:

\begin{tabular}{|l|l|l|}
\cline { 2 - 4 } \multicolumn{1}{c|}{} & \multicolumn{1}{|c|}{ Ação } & \multicolumn{1}{c|}{ Transformação } \\
\hline $\mathbf{1}$ & $\begin{array}{l}\text { Estabelecer a expressão que transforma o consumo } \\
\text { de café em 2009, de quantidade de xícaras para } \\
\text { mililitros (331 bilhões x 120 ml). }\end{array}$ & $\begin{array}{l}\text { Conversão da língua materna para o registro } \\
\text { numérico inteiro. }\end{array}$ \\
\hline $\mathbf{2}$ & Resolvera expressão $(39.600$ bilhões $\mathrm{mL})$. & Tratamento no registro numérico inteiro. \\
\hline $\mathbf{3}$ & $\begin{array}{l}\text { Estabelecer a expressão que calcula o consumo de } \\
\text { café em 2010, em mililitros } \\
\left(39.600 \text { bilhões } \mathrm{ml}+\frac{1}{5} \times 39.600 \text { bilhões ml). }\right.\end{array}$ & $\begin{array}{l}\text { Conversão do registro da língua materna } \\
\text { para o numérico fracionário. }\end{array}$ \\
\hline $\mathbf{4}$ & Calcular a expressão $(47.520$ bilhões ml). & Tratamento no registro numérico fracionário. \\
\hline $\mathbf{5}$ & $\begin{array}{l}\text { Transformação da unidade de capacidade mililitros } \\
\text { para litros (47.520 bilhões ml } \div 100)\end{array}$ & Tratamento no registro numérico Inteiro. \\
\hline
\end{tabular}

1.1) Outro tipo de solução seria transformar o consumo de café em 2009 para litros, inicialmente:

\begin{tabular}{|c|l|l|}
\cline { 2 - 4 } \multicolumn{1}{c|}{} & \multicolumn{1}{c|}{ Ação } & \multicolumn{1}{c|}{ Transformação } \\
\hline $\mathbf{1}$ & $\begin{array}{l}\text { Transformar a quantidade de café por xícara de } \\
\text { mililitros para litros.(120ml } \div 100)\end{array}$ & Tratamento no registro numérico inteiro. \\
\hline $\mathbf{2}$ & $\begin{array}{l}\text { Transformar o consumo de café em 2009, de xícaras } \\
\text { de café para litros }(330 \text { bilhões } \times 0,121) .\end{array}$ & Tratamento no registro numérico decimal. \\
\hline $\mathbf{3}$ & $\begin{array}{l}\text { Estabelecer a expressão que calcula o consumo de } \\
\text { café em em litros } \\
\left(39,6 \text { bilhões } 1 \times \frac{1}{5} \times 39,6 \text { bilhões } 1\right)\end{array}$ & $\begin{array}{l}\text { Conversão do registro da língua materna para } \\
\text { numérico decimal e fracionário e } \\
\text { tratamento no registro numérico fracionário e } \\
\text { decimal. }\end{array}$ \\
\hline
\end{tabular}

Ainda podem ser adotados outros tipo de resolução, em que a primeira ação, seria o cálculo do consumo de café em 2010, como veremos a seguir:

1.2)

\begin{tabular}{|l|l|lr|}
\cline { 2 - 5 } \multicolumn{1}{c|}{ Ação } & \multicolumn{3}{|c|}{ Transformação } \\
\hline $\mathbf{1}$ & $\begin{array}{l}\text { Estabelecer a expressão que calcula o consumo de xícaras } \\
\text { de café } \\
\text { (331 bilhões de xícaras }+\frac{1}{5} \times 331 \text { bilhões de xícaras). }\end{array}$ & $\begin{array}{l}\text { Conversão do registro da língua } \\
\text { materna para o numérico fracionário }\end{array}$ \\
\hline $\mathbf{2}$ & $\begin{array}{l}\text { Calcular o consumo de xícaras de café em 2010 (397,2 } \\
\text { bilhões de xícaras). }\end{array}$ & $\begin{array}{l}\text { Tratamento no registro numérico } \\
\text { fracionário e conversão para o } \\
\text { numérico decimal. }\end{array}$ \\
\hline $\mathbf{3}$ & $\begin{array}{l}\text { Transformar o consumo de xícaras de café em 2010 para } \\
\text { mililitros (397,2 x 120 ml). }\end{array}$ & $\begin{array}{l}\text { Tratamento no registro numérico } \\
\text { decimal }\end{array}$ \\
\hline $\mathbf{4}$ & $\begin{array}{l}\text { Transformar a quantidade consumida em 2010 de mililitros } \\
\text { de café para litros (47664 } \div \text { 100). }\end{array}$ & $\begin{array}{l}\text { Tratamento no registro numérico } \\
\text { inteiro. }\end{array}$ \\
\hline
\end{tabular}


2) Análise do suporte:

O suporte é um texto no registro da língua materna e apresenta um dado no registro numérico inteiro.

3) Estrutura do item:

\begin{tabular}{|l|l|}
\hline Ideia envolvida & Parte-todo \\
\hline Registro do enunciado & Língua materna, numérico inteiro e numérico fracionário \\
\hline Registro do suporte & Língua materna e numérico inteiro \\
\hline Registro do comando & Língua materna \\
\hline Registro das alternativas de resposta & Numérico inteiro e língua materna \\
\hline
\end{tabular}

4) Alguns comentários:

Entre as soluções descritas, consideramos a estratégia 1 como sendo aquela em que exige um menor custo cognitivo, pois segue a ordem em que se apresentam os dados no item, ou seja mantém, uma congruência semântica com o enunciado, e a segunda solução como sendo a de maior custo cognitivo, porque o sujeito não só não utiliza a ordem dos dados dispostos no texto, como, também, não parte diretamente para o cálculo do consumo do café em 2010, como requer o comando, detendo-se em encontrar, inicialmente, a unidade de capacidade (litro) a qual se referem as alternativas de resposta para a partir dela, ser calculado o consumo de café em 2009 e posteriormente o de 2010, imprimindo, assim, uma ordem inversa, que não é utilizada nas demais soluções.

\subsection{Síntese da análise das provas de matemática e suas tecnologias dos ENEM de 2009 à 2011}

Os itens referentes às provas de matemática e suas tecnologias dos ENEM de 2009 a 2011 tiveram um predomínio, na sua estrutura (enunciado, suporte, comando e alternativas de resposta), do registro numérico percentual (62,6\%). Entretanto, o ENEM 2011 apresentou um número bem maior de itens com o significado probabilidade, em relação às edições anteriores. Em relação ao procedimento de resolução, o significado porcentagem foi bem menos mobilizado que nas edições de 2009 e 2010.

O significado porcentagem no período relativo ao novo ENEM (2009-2011) aparece envolvido em vários contextos, inclusive envolvendo outros conceitos matemáticos, tais 
como área de figuras planas, trigonometria no triângulo retângulo e conceitos relativos à matemática financeira. O significado razão foi trabalhado em contextos envolvendo escala, velocidade média, comparação entre volume e medida de capacidade, e densidade demográfica. O significado probabilidade, como chances de escolha aleatória dentro de um universo, foi mobilizado em contexto geográfico, envolvendo dados populacionais, campanha de vacinação e pesquisa de tamanho de calçado. Portanto, constatamos que alguns itens fizeram conexões não só entre conceitos matemáticos, mas também com conceitos relacionados à física e à geografia. Alguns itens envolveram também mais de um significado.

No que tange aos registros semióticos dos números racionais, o que pôde ser mais mobilizado durante as resoluções dos itens dos ENEM 2009 a 2011, foi o registro numérico fracionário. Ao compararmos esse registro com os demais, em relação aos significados envolvidos nos itens, foi o que mais pôde ser mobilizado nas resoluções daqueles que envolveram o significado razão, parte-todo e probabilidade e, também, o segundo mais mobilizado nos itens que envolveram o significado porcentagem.

Quanto às conversões que puderam ser realizadas nas estratégias de resolução dos itens, com exceção de um item no ENEM 2010, essas ocorreram apenas em um sentido, ou seja, do registro de partida para um registro de chegada, e não a transformação inversa, em que o registro de chegada passa a ser o de partida. Entretanto, Duval $(2009,2011)$ afirma que saber converter num sentido, não implica, necessariamente, em saber realizar a conversão inversa.

Nas conversões que puderam ser realizadas nas resoluções dos itens identificados dos ENEM 2009 a 2011 que tiveram como registro de partida a língua materna, o registro de chegada que poderia ocorrer com maior frequência foi o numérico fracionário. Essas conversões puderam ser mobilizadas nos itens que envolveram os significados razão, parte-todo, porcentagem e probabilidade. As conversões que tiveram como registro de partida a língua materna e de chegada o numérico percentual ocorreram nos itens que abordaram o significado porcentagem e probabilidade.

No ENEM 2009 e 2010, em que o significado mais contemplado pelos itens foi o de porcentagem, verificamos que as conversões que puderam ser mobilizadas durante a resolução dos itens, com maior frequência, entre os registros dos números racionais, são aquelas que têm como registro de partida o numérico percentual e como registro de chegada o fracionário. 
No ENEM 2011, os itens que contemplam os significados que mais mobilizam o registro numérico fracionário (porcentagem, probabilidade e razão) estão distribuídos uniformemente entre o número de itens analisados, então verificamos que as conversões que mais podem ser mobilizadas têm como registro de partida o numérico fracionário e como registro de chegada o numérico decimal.

Nas conversões que puderam ser realizadas nas resoluções dos itens que envolveram outros tipos de registros como o registro algébrico e o que tipificamos de diagrama, a maior ocorrência ficou entre aquelas que envolveram como registro de partida a língua materna e o de chegada o registro em diagrama, como também a que converte o registro diagrama em algébrico, porque fizeram parte da estratégia que utiliza o raciocínio proporcional para resolução de itens que mobilizaram o significado porcentagem.

Nos itens em que o suporte era uma figura geométrica houve a necessidade da apreensão perceptiva e, em alguns casos, da apreensão discursiva, para relacionar o desenho com as propriedades da figura geométrica e o enunciado do item.

Alguns itens apresentaram no enunciado, comando, suporte e descritores uma congruência semântica que não possuía equivalência referencial com a resolução do item o que pode levar a um índice maior de erros destes.

\section{Considerações finais}

A análise das provas de conhecimentos gerais dos ENEM de 1998 a 2008 e das provas de matemática e suas tecnologias dos ENEM de 2009 a 2011 nos mostrou uma tendência do ENEM em abordar os significados dos números racionais, porcentagem, probabilidade, razão e parte-todo, podendo ser justificada devido a ao fato de o ENEM priorizar situações que envolvam contextos econômicos e sociais, ou seja, relacionados à cidadania, nos quais os significados porcentagem, razão e probabilidade podem se fazer mais frequentes.

O registro numérico fracionário se mostrou o que mais pôde ser mobilizado nas estratégias de resolução dos itens e, também, o que mais se apresentou como registro de chegada, nas conversões em que o registro de partida é a língua materna, pois esse registro foi o mais frequente entre os significados, probabilidade, razão, parte-todo e o segundo mais frequente nos itens que envolvem o significado porcentagem. 
Esse fato reflete a diversidade de contextos que podem apresentar o registro numérico fracionário e a necessidade de sua compreensão em cada um deles. Mostra, também, a necessidade de saber converter desse registro para o numérico decimal, no caso de se querer expressar um índice de probabilidade, por exemplo; ou para o numérico percentual, quando se deseja um percentual; ou ainda para o registro figural, quando o item requer expressar uma parte tomada de um todo. Como vimos anteriormente, é de fundamental importância saber converter desses registros para o numérico fracionário, demonstrando, assim, coordenação entre eles.

O ENEM 2011, diferentemente dos ENEM 2009 e 2010 que apresentaram uma predominância de itens que abordaram o significado porcentagem, demonstrou uma uniformidade no número de itens que abordam os significados porcentagem, probabilidade e razão. Seria importante analisar as versões posteriores, para verificar se existe uma tendência nessa direção.

Além da análise realizada nesse estudo quanto aos registros de representações semióticas dos números racionais, acreditamos ser importante uma análise mais criteriosa quanto à congruência semântica e equivalência referencial do enunciado, comando, suporte e descritores dos itens, como fator que influência na estratégia de resolução e, também no índice de acertos.

\section{Referências bibliográficas}

Ministério da Educação. Instituto Nacional de Estudos e Pesquisas Educacionais Anísio Teixeira. Exame Nacional do Ensino Médio: Prova de Redação e de Linguagens, códigos e suas Tecnologias e Prova de Matemática e suas Tecnologias.

Brasília, DF, cad. 7, 2009(d). Disponível em: $<$ http://portal.inep.gov.br/web/enem/edicoes-anteriores $>$. Acessado em: 16/08/2010.

Ministério da Educação. Instituto Nacional de Estudos e Pesquisas Educacionais Anísio Teixeira. Exame Nacional do Ensino Médio: Prova de Redação e de Linguagens, códigos e suas Tecnologias e Prova de Matemática e suas Tecnologias. Brasília, DF, cad. 5, 2010. <http://portal.inep.gov.br/web/enem/edicoes-anteriores >. Acessado em: 02/04/2011.

- Ministério da Educação. Instituto Nacional de Estudos e Pesquisas Educacionais Anísio Teixeira. Exame Nacional do Ensino Médio: Prova de Redação e de Linguagens, códigos e suas Tecnologias e Prova de Matemática e suas Tecnologias. 
Brasília, DF, cad. 5, 2011. <http://portal.inep.gov.br/web/enem/edicoes-anteriores>. Acessado em: 22/05/2012.

CATTO, G. G. Registros de representação e o número racional - Uma abordagem nos livros didáticos. São Paulo, 2000. 152p. Dissertação (Mestrado em Educação Matemática). Pontifícia Universidade Católica de São Paulo, 2000.

DUVAL, R. Registros de representação e números racionais. In: MACHADO, S. D. A. (Org.). Aprendizagem em matemática: Registros de representação semiótica. Campinas: Papirus, p. 11-33, 2003.

Semiósis e Pensamento Humano: Registros semióticos e aprendizagens intelectuais. Coleção Contextos da Ciência. Fasc. I. $1^{a}$ ed. São Paulo: editora Livraria da Física, 2009.

. Ver e ensinar a matemática de outra forma: Entrar no modo matemático de pensar: os registros de representações semióticas. 1ª ed. São Paulo: PROEM, 2011.

Diferenças semânticas e coerência matemática: introdução aos problemas de congruência. REVEMAT. Florianópolis, Santa Catarina, v. 7, n. 1, p. 97-117, 2012 a.

Abordagem cognitiva de problemas de geometria em termos de congruência. REVEMAT. Florianópolis, Santa Catarina, v. 7, n.1, p. 118-138, 2012 b.

GOMES, R. Q. G. Saberes docentes de professores dos anos iniciais sobre frações. Rio de Janeiro, 2010. 112p. Dissertação (Mestrado em Ensino de Matemática). Instituto de Matemática, Universidade Federal do Rio de Janeiro, 2010.

MARANHÃO, M. C. S. A; IGLIORI, S. B. C. Registros de representação e números racionais. In: MACHADO, S. D. A. (Org.). Aprendizagem em matemática: Registros de representação semiótica. Campinas: Papirus, 2003. cap. 4, p. 57-70.

MERLINI, V. L. O conceito de fração em seus diferentes significados: um estudo diagnóstico com alunos de $5^{\mathrm{a}}$ e $6^{\mathrm{a}}$ séries do Ensino Fundamental. São Paulo, 2005. 215p. Dissertação (mestrado em Educação matemática). Pontifícia Universidade Católica de São Paulo, 2005.

RAMALHO, B. L.; NÚÑEZ, I. B. Fundamentos do ensino-aprendizagem das ciências naturais e da matemática: as provas do ENEM como referência para o Ensino Médio. In: (Organizadores). Aprendendo com o ENEM - Reflexões para melhor se pensar o ensino e a aprendizagem das ciências naturais e da matemática. Brasília: Liber Livro Editora, 2011. Apresentação, p. 7-15.

ROMANATTO, M. C. Número Racional: Relações necessárias à sua compreensão. Campinas, 1997. 158p. Tese (Doutorado em Educação). Faculdade de Educação, Universidade Estadual de Campinas, 1997.

TEIXEIRA, A. M. O professor, o ensino de fração $e$ o livro didático: um estudo investigativo. São Paulo, 2008. 194p. Dissertação (mestrado Profissional em Educação matemática). Pontifícia Universidade Católica de São Paulo, 2008. 